\title{
Trajectories of maternal depressive symptoms and offspring's risk behavior in early adolescence: data from the 2004 Pelotas birth cohort study
}

Ana Beatriz Bozzini ${ }^{1 *}$, Jessica Mayumi Maruyama', Tiago N. Munhoz ${ }^{2,3}$, Aluísio J. D. Barros², Fernando C. Barros ${ }^{4}$, Iná S. Santos ${ }^{5}$ and Alicia Matijasevich ${ }^{1,2}$

\begin{abstract}
Background: This longitudinal study explored the relationship between trajectories of maternal depressive symptoms and offspring's risk behavior in adolescence contributing to an extremely scarce literature about the impacts of maternal depression trajectories on offspring risk behaviors.

Methods: We included 3437 11-year-old adolescents from the 2004 Pelotas Birth Cohort Study. Trajectories of maternal depressive symptoms were constructed using Edinburgh Postnatal Depression Scale (EDPS) from age 3 months to 11 years. We identified five trajectories of maternal depressive symptoms: "low" "moderate low", "increasing", "decreasing", and "chronic high". The following adolescent outcomes were identified via self-report questionnaire and analyzed as binary outcome -yes/no: involvement in fights and alcohol use at age 11. We used logistic regression models to examine the effects of trajectories of maternal depressive symptoms on offspring's risk behavior adjusting for potential confounding variable.

Results: Alcohol use and/or abuse as well as involvement in fights during adolescence, were not significantly associated with any specific trajectory of maternal depressive symptoms neither in the crude nor in the adjusted analyses.
\end{abstract}

Conclusion: Alcohol use and involvement in fights at age 11 were not associated with any specific trajectory of maternal depression.

Keywords: Adolescent behavior, Risk -taking, Cohort studies

\section{Background}

Adolescence is marked by complex biological and psychological transformations that potentially could lead to risky, health-compromising behaviors and cause physical and mental impairments. These behaviors include exposure to violence, sexual risk behavior and the use of

\footnotetext{
* Correspondence: anabeatrizbozzini@gmail.com

'Departamento de Medicina Preventiva, Faculdade de Medicina FMUSP, Universidade de São Paulo, São Paulo, Brazil

Full list of author information is available at the end of the article
}

tobacco, alcohol and illicit substances [1]. Many of these activities are often sporadic, but if a consolidating pattern of risky behavior is not early identified and effectively monitored, the individual's health as well as her/his social and family ties may be severely harmed. There is an increased interest in studying risk behavior in adolescents due to its correlation with morbidity and mortality in adult life $[1,2]$.

The majority of studies about risk behavior in adolescence report current associated factors, particularly

C C The Author(s). 2021 Open Access This article is licensed under a Creative Commons Attribution 4.0 International License, which permits use, sharing, adaptation, distribution and reproduction in any medium or format, as long as you give appropriate credit to the original author(s) and the source, provide a link to the Creative Commons licence, and indicate if changes were made. The images or other third party material in this article are included in the article's Creative Commons licence, unless indicated otherwise in a credit line to the material. If material is not included in the article's Creative Commons licence and your intended use is not permitted by statutory regulation or exceeds the permitted use, you will need to obtain permission directly from the copyright holder. To view a copy of this licence, visit http://creativecommons.org/licenses/by/4.0/ The Creative Commons Public Domain Dedication waiver (http://creativecommons.org/publicdomain/zero/1.0/) applies to the data made available in this article, unless otherwise stated in a credit line to the data. 
sociodemographic determinants such as neighborhood characteristics, peer influence and family's socioeconomic status [3, 4]. Early determinants of risk behaviors are poorly explored, although it is well established that early infancy experiences can leave a lasting signature affecting emerging brain architecture and long-term health [5]. The literature describes three sets of early determinants that impact a child's future behavior: prenatal exposures such as maternal depression, tobacco, alcohol, caffeine and others substances' use during pregnancy; birth conditions such as prematurity and low birth weight; and adverse experiences during early life, such as maltreatment, neglect, family violence, adoption, and maternal or caregiver's emotional problems - including maternal postpartum depression [6-9].

Maternal depression after childbirth is a serious public health problem and has been explored in longitudinal studies as a predictor of emotional and mental problems in offspring [10-12]. Evidence suggests that children born from untreated depressed mothers (compared to mothers without maternal depression) are at greater risk to present behavioral inhibition, emotional maladjustment, violent behavior, externalizing problems, and psychiatric disorders in adolescence [13, 14]. Recently, studies evaluated not only 'severity' or 'timing', but also the 'course' of maternal depression and its impact on offspring's emotional and behavioral outcomes $[11,15,16]$.

Studies about trajectories of maternal depression, in general, identify two to six trajectories $[11,13,15,16]$, from none or minimal depressive symptoms to high chronic symptomatology. They mostly reported that children from mothers belonging to chronic and severe depressive symptoms trajectories were at more risk to present emotional problems when compared to those from mothers with low depressive symptomatology, even after adjusting for potential confounders [15, 17]. It is therefore suggestive that the identification and the treatment of maternal depressive symptomatology needs to be extended throughout the offspring's life course and not be restricted to the immediate postpartum period $[18,19]$.

Maternal depression is reported as an early risk factor for aggressive behavior [9], depressive symptoms [9], smoking tobacco [4] and alcohol consumption in adolescence [7]. Although maternal depression after childbirth and its association with individual risk-taking behaviors in adolescence has been studied previously, trajectories of maternal depression and risk behaviors in adolescence has been poorly explored. There exist multiple complex pathways through which maternal depression is associated with risk behavior in offspring, including genetic, neurobiological and social pathways. The aim of this study is to evaluate whether the course and severity of maternal depressive symptomatology impacts on risk behavior at age 11, considering potential confounders. We hypothesized that adolescents exposed to high levels of maternal depressive symptomatology throughout childhood and adolescence would engage in more health risk behavior than those exposed to low levels of maternal depressive symptoms.

\section{Method \\ Participants}

The 2004 Pelotas Birth Cohort is a population-based birth cohort of children born in the city of Pelotas, Southern of Brazil, from Jan 1, 2004 to Dec 31, 2004. All hospital births throughout that year were identified during daily visits to the city's five maternity hospitals [20]. 4231 live births of mothers living in the urban area of Pelotas (non-response rate at recruitment was <1\%) were recruited. Trained interviewers administered a structured questionnaire to obtain information on demographic, socioeconomic, biological and behavioral characteristics. The detailed methodology was described elsewhere [20, 21].

\section{Main exposure: maternal depressive symptoms}

Maternal depressive symptoms were assessed by the Edinburgh Postnatal Depression Scale (EPDS) [22]. The EPDS is a self - report, 10-item scale (score range: $0-30$, with higher scores indicating more severe depressive symptoms) that expresses the intensity of depressive symptoms over the preceding 7 days. We used a previously translated and validated version of the questionnaire [23]. Follow-up assessments were made at home at mean (standard deviation) ages $3.0(0.1), 11.9$ (0.2), 23.9 (0.4) and 49.5 (1.7) months and at a research clinic at $6.8(0.3)$ and $11.0(0.3)$ years, with follow-up rates between 87 and $96 \%$. The EPDS was administered to almost all mothers at each follow-up, except at the 3month follow-up when it was completed by a subsample of 965 mothers. The EPDS scores from 3 months to 11year follow-up was used to construct the trajectories of maternal depression through a semiparametric groupbased modelling approach [24]. We identified five trajectories of maternal depressive symptoms: "low" trajectory group is represented by a linear trajectory comprising women with EPDS $<10$ across all time points. The "moderate low" group is represented by a quadratic trajectory comprising mother with EPDS< 10 across all time points. The "increasing" group is composed by women who showed a consistent increase in depressive symptoms during the study period and the "decreasing" group comprises women who showed high EPDS scores in the first 2 years postpartum and a marked decrease afterwards. Finally, the "chronic high" trajectory demonstrated high EPDS scores all through the study period $[11,13,15,16]$. 
More details of the steps and methods used to identify the trajectories of maternal depressive symptoms were reported in previous studies $[15,25]$. Briefly, $90 \%$ of the sample population completed the EPDS at least three times and $17 \%$ of mothers completed the EPDS in all follow ups. We included 3347 mothers with data from at least three follow-ups in the analyses.

\section{Main outcomes: risk behaviors in adolescence}

We evaluated two different outcomes of adolescents at age 11. Involvement in fights was accessed via selfreport questionnaire with the following question: "Did you get into a fight where someone got injured in the last year?" The answer was analyzed as a binary outcome - yes/ no. Alcohol use was accessed via self-report questionnaire with the following questions: "Have you ever drank alcohol?". The answer was analyzed as a binary outcome - yes/ no.

\section{Covariates}

Information about maternal, pregnancy, family and child characteristics were collected at the perinatal interview. Socioeconomic and maternal characteristics were: monthly family income in the month prior to delivery (quintiles); maternal schooling (number of completed years of formal education, categorized as $0-4,5-8$, and $\geq 9$ years); maternal self-reported skin color (white or non-white); maternal age at childbirth $(<20,20-34, \geq 35$ years old); marital status (single mother or living with a partner); maternal emotional support received from partner during pregnancy (yes/no); parity (the number of previous viable pregnancies resulting in a live birth or a late fetal death, categorized as 0,1 or $\geq 2$ ). Smoking and alcohol use during pregnancy were self-reported and were evaluated retrospectively at birth. Women were categorized as having smoked during pregnancy if they reported smoking at least one cigarette per day during any trimester. Women were categorized as having used alcohol during pregnancy if they reported any alcohol use during any trimester. Women were asked when their prenatal care began (first, second or third trimester) and if they planned their pregnancy (yes/no). Maternal mood symptoms during pregnancy was defined as "present" if the mother answered positively to the following question: "During pregnancy, did you feel depressed or have any nervous condition?". Type of delivery was classified as vaginal or caesarean section.

The father's presence during child's life was reported by mothers at 24-month and 48-month follow-up and categorized as "never absent", "absent sometimes" and "always absent". Child variables were: sex; low birthweight $(<2.500 \mathrm{~g})$; gestational age $(\leq 36,37-41$ or $\geq 42$ weeks); 5 min Apgar score ( $<7$ or $\geq 7)$; breastfeeding duration was reported by mothers at the 24-month follow- up ( $\geq 4$ month or $<4$ months); number of siblings older or younger than the cohort participant assessed at the 11-year follow-up $(0,1,2,3$ or $\geq 4)$; child's hospitalization during 1st year of life (yes/no); Intelligence Quotient (IQ) assessed by the Wechsler Intelligence Scale for Children- III (WISC-III) at age six and categorized as high average $(>0.75 \mathrm{SD})$, average $(-$ 0.75 to $0.75 \mathrm{SD})$ and low average $(<-0.75 \mathrm{SD})$ [26].

\section{Statistical analysis}

We conducted a descriptive analysis of adolescents and mother's characteristics among those included and not included in the present analyses. Bivariate analysis was conducted to compare characteristics between the two groups. We used chi square test for categorical variables and ANOVA for continuous variables.

All outcomes were analyzed as binary variables. Bivariate analyses were conducted to identify potential confounding variables. Multivariable logistic regression was conducted to evaluate the association between trajectories of maternal depression and risk behaviors at age 11, adjusting for selected confounding variables in separate models. We considered the 'trajectories of maternal depressive symptoms' as a proximal determinant of risk behaviors and depression in adolescence with effects that could be confounded by distal variables. Potential confounding variables were included as covariates if they were significantly associated with the main exposure (maternal depression trajectories) and outcome of interest and were not part of the causal chain. They were grouped and included in the adjusted analysis using a backward strategy selection [27]. Five models were included for each outcome: unadjusted results (model 1), model $1+$ socioeconomic variables (model 2 ), model $2+$ maternal variables (model 3 ), model $3+$ pregnancy and delivery variables (model 4 ) and model $4+$ paternal and child variables (model 5 ). If the significance level was below 0.20 , the variable remained in the model as a potential confounder for the next level. All analyses were performed with Stata software version 14.2 (StataCorp LP, College Station, Tex).

The study was approved by the Research Committee of the University of São Paulo School of Medicine, and by the Research Ethics Committee of the Federal University of Pelotas. Written informed consent was obtained from the mothers or legal guardians of the adolescents. At the 11-year follow-up, adolescents signed an informed consent form.

\section{Results}

\section{Attrition analysis}

The original cohort has 4231 participants, and of those, 98 died in the first 11 years of life and 3566 were interviewed at 11 years. Data about the outcomes and main 
exposure were available for 3347 individuals, representing $79,1 \%$ of the original cohort. Women who were included in the present study were highly educated; less likely to be single, to be in the lowest quintile of income, and to present mood symptoms during pregnancy. The proportion of women that started prenatal care in the first semester of pregnancy was higher among those included than those notincluded. Included and nonincluded women did not differ significantly in age, alcohol and tobacco consume during pregnancy. We also noticed a similar proportion of those mothers who reported that they had planned their pregnancies. Adolescents included in the present analyses had higher birthweight and lower frequencies of 5 min Apgar score $<7$ and prematurity than those not included (Table 1).

Table 5 (supplementary material) shows the differences in socioeconomic, maternal and child characteristics between those participants interviewed in both fifth and sixth followup waves (at age 6 and age 11) and those interviewed in the fifth follow-up wave (at age 6), but absent in the sixth followup wave (at age 11). Adolescents who attended the fifth follow-up, but did not participate in the last follow-up were more likely to be born from a white woman, belong to families from the lowest quintile of income and to be female.

\section{Risk behaviors in adolescents (outcomes) - descriptive analysis}

Of the 3347 individuals included in the present study, 475 (14.1\%) have been involved in fights and 269 (8.0\%) have already used alcohol (Table 2).

\section{Maternal depression trajectories}

Groups "low" representing 32.7\% (CI 95\% 31.2-34.3) of the women and "moderate-low" containing 42.3\% (CI 95\% 40.7-44.0) of the women, included mothers with EPDS scores below 10 across all time points. Group "increasing" included $11.2 \%$ (CI 95\% 10.2-12.3) of the women that had a consistent increase in depressive symptoms during the study period. The group "decreasing", containing $8.8 \%$ (CI 95\% 7.9-9.8\%) of the sample, was constituted by women that showed high EPDS scores in the first 2 years postpartum and a marked decrease afterward. The group "chronic high" included $4.9 \%$ (CI 95\% 4.2-5.7\%) of the sample and represents those mothers with high EPDS scores across the 11-year period.

\section{Other factors associated with maternal depression trajectory membership}

We investigated whether maternal depression trajectory groups differed on maternal and child characteristics (Table 3). Women in the "chronic high" depression trajectory group were more frequently multiparous, more likely to have an unplanned pregnancy and more likely to report low emotional support received from their partners during pregnancy. They also reported the highest frequencies of mood symptoms and alcohol and tobacco consumption during pregnancy.

Regarding child characteristics, low birthweight, sex and Apgar score did not vary by maternal depression

Table 1 Comparison of maternal and child characteristics between those included and not included in the present study, 2004 Pelotas Birth Cohort

\begin{tabular}{|c|c|c|c|}
\hline Variables & $\begin{array}{l}\text { Included } \\
(n=3347)\end{array}$ & $\begin{array}{l}\text { Not included } \\
(n=882)\end{array}$ & $p$-value* \\
\hline Family income, lowest quintile(\%) & 19.3 & 25.5 & $<0.001$ \\
\hline Schooling (years), mean (sd) & $8.1(3.4)$ & $7.8(3.7)$ & $0.002^{* *}$ \\
\hline Maternal skin colour, white(\%) & 73.3 & 72.0 & 0.930 \\
\hline Maternal age (years),mean (sd) & $26.2(6.8)$ & $25.5(6.5)$ & $0.118^{* *}$ \\
\hline Single mother(\%) & 15.4 & 19.9 & 0.001 \\
\hline Parity $\geq 2(\%)$ & 33.5 & 37.2 & 0.079 \\
\hline Smoking during pregnancy(\%) & 74.9 & 72.5 & 0.156 \\
\hline Alcohol during pregnancy(\%) & 3.1 & 4.1 & 0.150 \\
\hline Started prenatal care in the 1sttrimester (\%) & 73.9 & 68.8 & 0.011 \\
\hline Planned pregnancy(\%) & 43.8 & 41.4 & 0.205 \\
\hline Mood symptoms during pregnancy(\%) & 24.0 & 28.9 & 0.003 \\
\hline C-section(\%) & 44.9 & 47.0 & 0.275 \\
\hline Child sex, male (\%) & 51.4 & 53.5 & 0.282 \\
\hline Low birth weight(\%) & 8.3 & 16.5 & $<0.001$ \\
\hline Preterm birth < 37w(\%) & 13.4 & 19.2 & $<0.001$ \\
\hline 5 min Apgar score $<7(\%)$ & 1.3 & 5.2 & $<0.001$ \\
\hline
\end{tabular}


Table 2 Adolescent's outcomes at age 11 by trajectories of maternal depression, $N=3347$

\begin{tabular}{|c|c|c|c|c|c|c|c|}
\hline & $\begin{array}{l}\text { Low } \\
N=1096 \\
(\mathrm{~N}, \%, \mathrm{Cl} 95 \%)\end{array}$ & $\begin{array}{l}\text { Moderate Low } \\
N=1417 \\
(\mathrm{~N}, \%, \mathrm{Cl} 95 \%)\end{array}$ & $\begin{array}{l}\text { Increasing } \\
N=375(\mathrm{~N}, \\
\%, \mathrm{Cl} 95 \%)\end{array}$ & $\begin{array}{l}\text { Decreasing } \\
N=295 \\
(\mathrm{~N}, \%, \mathrm{Cl} 95 \%)\end{array}$ & $\begin{array}{l}\text { Chronic High } \\
N=164 \\
(\mathrm{~N}, \%, \mathrm{Cl} 95 \%)\end{array}$ & $\begin{array}{l}\text { Absolute } \\
\text { frequency } \\
N=3347 \\
(\mathrm{~N}, \%, \mathrm{Cl} 95 \%)\end{array}$ & $\begin{array}{l}\text { Frequency(\%) } \\
(\%, \mathrm{Cl} 95 \%)\end{array}$ \\
\hline $\begin{array}{l}\text { Involvement in } \\
\text { fights }\end{array}$ & $\begin{array}{l}140(12.6,10.8- \\
14.7)\end{array}$ & $\begin{array}{l}208(14.5,12.8- \\
16.4)\end{array}$ & $\begin{array}{l}61(16.1,12,7- \\
20.2)\end{array}$ & $\begin{array}{l}48(15.6,11.9- \\
20.1)\end{array}$ & $\begin{array}{l}19(11.5,7.4- \\
17.4)\end{array}$ & $475(14.0)$ & $\begin{array}{l}14.0(12.9- \\
15.2)\end{array}$ \\
\hline Alcohol use & $78(6.9,5.6-8.6)$ & $\begin{array}{l}122(8.5,7.1- \\
10.0)\end{array}$ & $39(10.2,7.6-13,7)$ & $\begin{array}{l}24(7.9,5.3-11 \\
5)\end{array}$ & $\begin{array}{l}14(8.3,5.0- \\
13.6)\end{array}$ & $269(8.0)$ & $8.0(7.1-9.0)$ \\
\hline
\end{tabular}

trajectories groups. Having four or more siblings, presenting a low average IQ and a breastfeeding duration less than 4 months were more frequent among those adolescents whose mother presented a "chronic high" depression trajectory.

\section{Risk behaviors at 11 years and maternal depression} trajectories

We conducted logistic regression analyses to examine the crude and adjusted association between maternal depressive trajectory groups and adolescent risk behaviors (Table 4). We found that 'involvement in fights' and 'alcohol experimentation' were not associated with any specific trajectory of maternal depression.

\section{Discussion}

Our study observed that alcohol use and/or abuse, as well as involvement in fights during adolescence, were not significantly associated with any specific trajectory of maternal depression neither in the crude nor in the

Table 3 Maternal and child characteristics according to maternal depression trajectory

\begin{tabular}{|c|c|c|c|c|c|c|}
\hline \multirow[t]{2}{*}{ Variables } & \multicolumn{5}{|c|}{$\begin{array}{l}\text { Maternal depression trajectory } 3 \mathrm{~m}-11 \mathrm{y} \\
(\mathrm{N}, \%)\end{array}$} & \multirow[t]{2}{*}{$\begin{array}{l}p- \\
\text { value* }\end{array}$} \\
\hline & $\begin{array}{l}\text { "Low" } \\
N=1096\end{array}$ & $\begin{array}{l}\text { "Moderate Low" } \\
N=1417\end{array}$ & $\begin{array}{l}\text { "Increasing" } \\
N=375\end{array}$ & $\begin{array}{l}\text { "Decreasing" } \\
N=295\end{array}$ & $\begin{array}{l}\text { "Chronic high" } \\
N=164\end{array}$ & \\
\hline \multicolumn{7}{|l|}{ Maternal variables } \\
\hline Family income ( $5^{\text {th }}$ quintile $)$ & 26.9 & 18.6 & 11.2 & 10.8 & 8.5 & $<0.001$ \\
\hline Schooling $>=9$ years & 55.6 & 45.4 & 25.4 & 28.3 & 17.7 & $<0.001$ \\
\hline Skin colour, White & 76.9 & 73.3 & 64.8 & 69.4 & 69.5 & $<0.001$ \\
\hline Single mother & 12.5 & 16.5 & 17.8 & 18.3 & 14.6 & 0.015 \\
\hline Maternal age $<20$ years & 15.2 & 20.1 & 22.6 & 24.7 & 14.6 & 0.001 \\
\hline Parity $>=2$ & 27.9 & 31.1 & 42.1 & 37.9 & 64.6 & $<0.001$ \\
\hline No emotional support during pregnancy & 10.8 & 16.4 & 22.0 & 23.2 & 26.5 & $<0.001$ \\
\hline Unplanned pregnancy & 50.7 & 55.8 & 62.1 & 63.0 & 68.2 & $<0.001$ \\
\hline Smoking during pregnancy & 17.6 & 24.4 & 34.1 & 35.2 & 42.0 & $<0.001$ \\
\hline Alcohol use during pregnancy & 2.0 & 3.0 & 2.9 & 4.0 & 9.1 & $<0.001$ \\
\hline Depression during pregnancy & 10.0 & 23.4 & 36.5 & 42.0 & 61.5 & $<0.001$ \\
\hline Started prenatal care in the 1sttrimester & 79.3 & 72.7 & 70.7 & 68.0 & 65.4 & $<0.001$ \\
\hline C-section & 47.8 & 44.2 & 41.6 & 44.0 & 42.0 & 0.182 \\
\hline \multicolumn{7}{|l|}{ Child variables } \\
\hline Sex, male (\%) & 50.5 & 52.7 & 53.0 & 50.1 & 45.7 & 0.406 \\
\hline Low birthweight & 9.3 & 7.0 & 9.6 & 9.8 & 7.3 & 0.181 \\
\hline Preterm birth (<37 weeks) & 11.6 & 12.9 & 17.6 & 15.2 & 17.0 & 0.021 \\
\hline 5 min Apgar $<7$ & 1.7 & 0.9 & 2.1 & 0.6 & 1.8 & 0.239 \\
\hline Sibling number $>=4$ & 3.4 & 4.7 & 6.7 & 5.9 & 10.0 & $<0.001$ \\
\hline IQ low average & 16.7 & 23.8 & 29.5 & 31.5 & 37.8 & $<0.001$ \\
\hline Hospitalization 1st year of life & 13.7 & 17.8 & 21.0 & 24.7 & 23.9 & $<0.001$ \\
\hline Breastfed $<4$ months & 22.2 & 21.9 & 26.0 & 24.6 & 32.7 & 0.018 \\
\hline
\end{tabular}


Table 4 Crude and adjusted logistic regression analysis for risk behaviors (involvement in fights and alcohol use) according to the trajectories of maternal depressive symptoms (children from mothers in "low" group = reference), 2004 Pelotas Birth Cohort

\begin{tabular}{|c|c|c|c|c|c|c|c|}
\hline & Models & $\begin{array}{l}\text { Low } \\
\text { OR(95\%Cl) }\end{array}$ & $\begin{array}{l}\text { Moderate low } \\
\text { OR( }(95 \% \mathrm{Cl})\end{array}$ & $\begin{array}{l}\text { Increasing } \\
\text { OR(95\%Cl) }\end{array}$ & $\begin{array}{l}\text { Decreasing } \\
\text { OR( }(95 \% \mathrm{Cl})\end{array}$ & $\begin{array}{l}\text { Chronic high } \\
\text { OR(95\%Cl) }\end{array}$ & $P$-value \\
\hline \multirow[t]{5}{*}{ Involvement in fights } & Model 1 & 1.0 & $1.2(0.9-1.5)$ & $1.3(1.0-1.8)$ & $1.3(0.9-1.9)$ & $0.9(0.5-1.5)$ & 0.308 \\
\hline & Model $2^{a}$ & 1.0 & $1.1(0.9-1.5)$ & $1.3(1.0-1.9)$ & $1.3(0.9-1.9)$ & $0.9(0.5-1.5)$ & 0.293 \\
\hline & Model $3^{b}$ & 1.0 & $1.1(0.9-1.4)$ & $1.3(0.9-1.9)$ & $1.3(0.9-1.8)$ & $0.9(0.5-1.5)$ & 0.432 \\
\hline & Model $4^{c}$ & 1.0 & $1.1(0.9-1.4)$ & $1.2(0.9-1.7)$ & $1.2(0.8-1.7)$ & $0.8(0.4-1.3)$ & 0.845 \\
\hline & Model $5^{\mathrm{d}}$ & 1.0 & $1.1(0.8-1.4)$ & $1.3(0.9-1.9)$ & $1.1(0.7-1.7)$ & $0.8(0.4-1.4)$ & 0.766 \\
\hline \multirow[t]{5}{*}{ Alcohol use } & Model 1 & 1.0 & $1.2(0.9-1.7)$ & $1.6(1.0-2.4)$ & $1.1(0.7-1.9)$ & $1.1(0.6-2.0)$ & 0.329 \\
\hline & Model $2^{a}$ & 1.0 & $1.2(0.9-1.7)$ & $1.5(1.0-2.3)$ & $1.1(0.7-1.8)$ & $1.0(0.5-1.9)$ & 0.486 \\
\hline & Model $3^{e}$ & 1.0 & $1.2(0.9-1.7)$ & $1.5(1.0-2.3)$ & $1.1(0.7-1.8)$ & $1.0(0.5-1.9)$ & 0.433 \\
\hline & Model $4^{f}$ & 1.0 & $1.2(0.9-1.7)$ & $1.5(1.0-2.3)$ & $1.1(0.7-1.8)$ & $1.0(0.5-1.9)$ & 0.525 \\
\hline & Model $5^{9}$ & 1.0 & $1.3(0.9-1.7)$ & $1.5(1.0-2.3)$ & $1.1(0.7-1.8)$ & $0.9(0.5-1.8)$ & 0.584 \\
\hline
\end{tabular}

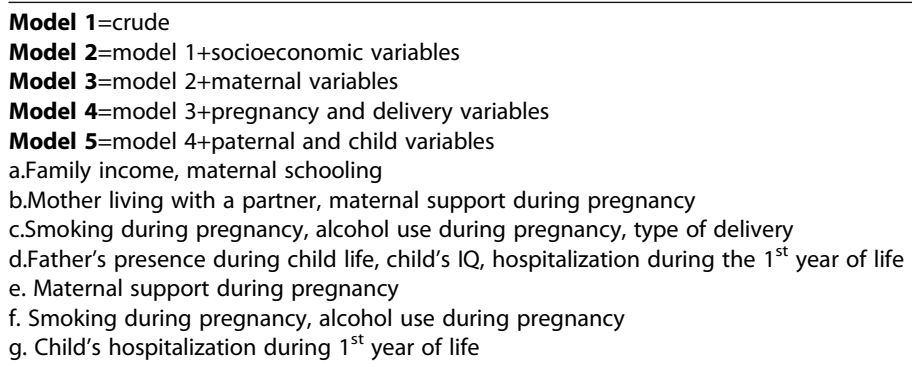

adjusted analyses. Although the consequences of chronic and recurrent maternal depression on offspring risk behavior are well known [28-30], most studies have addressed incompletely the impact of the 'course' and 'severity' of maternal depression on adolescent. We identified few longitudinal studies that investigated the impact of the trajectories of maternal depression on adolescent's risk behavior [31-33].

It has been already described in longitudinal studies that maternal depression during the first years of a child's life is a risk factor for several risk behaviors in adolescence such as alcohol and/or tobacco experimentation; and aggressive behavior $[9,34,35]$. However, to the best of our knowledge, only three studies have investigated the role of longitudinal patterns of maternal depressive symptomatology on adolescent's risk behaviors [31-33], and only one of them addressed the engagement in risk behavior in early adolescence - at age 11 [35] .

Wickham et al. (2015) [31] demonstrated that adolescents exposed to severe maternal symptoms throughout childhood ( 4 to 8 years) were more likely to engage in violent and nonviolent delinquent behavior at age 16 . This group of adolescents also reported earlier age of onset of cigarette, alcohol, marijuana and hallucinogen use when compared to adolescents of mothers in other depression trajectories groups. Nevertheless, when the exposition to severe maternal depressive symptoms occurs in early adolescence, they did not find an increased risk of engagement in risk behaviors. They demonstrated that 'severity' of maternal depressive symptomatology is an important risk factor for risk behavior in adolescents only if it occurs during middle childhood - a sensitive period when the effects of adverse experiences are particularly strong in child's development. In our study, we did not disentangle 'timing' from 'chronicity' and further longitudinal studies will be necessary to elucidate the association about the 'timing' of maternal depressive symptomatology occurrence and risk behavior outcomes in offspring.

Campbell et al. (2009) [33] investigated the association between trajectories of maternal depression and several outcomes in adolescents including 'engagement in risky behavior'. The outcome 'engagement in risky behaviors' was accessed by a self-reported combining items questionnaire - a measure created specifically for their study. Adolescents were asked how often in the past year they had engaged in a series of mildly to seriously risky behaviors (e.g skipped school without permission, taken part in gang fight, smoked marijuana, sold drugs, had sexual intercourse). They found that, at age 15, adolescents whose mothers were in the chronic, elevated, and stable subclinical latent classes reported engaging in more risk behavior than did adolescents of never depressed mother. However, the authors addressed that they could not explain the mechanism by which severity and chronicity of maternal depression enhance the odds of engagement in risky behavior, and added that, probably, there are many other covariates that could influence the finding but were not considered in their study. 
Finally, Flouri et al. (2017) [32] investigated the role of different trajectories of maternal depressive symptoms at child ages 3-11 years in offspring risky behaviors such as delinquency and alcohol use, at age 11, using empirical sex stratified models. The study demonstrated that in females, exposure to chronically high maternal depressive symptoms was associated with the view that alcohol use is harmless. In males, exposure to chronically high maternal depressive symptoms was related to aggressive behavior and alcohol use. They concluded that preventing or treating high maternal depressive symptoms in childhood may be an effective strategy for reducing a range of common risky behaviors in early adolescent males and it may also be useful in reducing alcohol use in early adolescent females. Nevertheless, the authors pointed out that the reason for the finding could be biased. First, because the measure of maternal depressive symptomatology used in the study was a measure of psychological distress rather than depression; second because maternal depressive symptoms also co-occur with family stress and less engaged and supportive parenting that could not be measured but probably influence adolescent's risky behavior.

Differently from the existing literature [31-33], we observed that the occurrence of 'alcohol use' as well as 'involvement in fights' did not vary according to any specific trajectory of maternal depressive symptomatology. This divergency may have occurred for several reasons: First, because our analyses were adjusted for several covariates such as paternal, maternal, child, pregnancy and delivery characteristics; and not only for gender and socioeconomic covariates as in other previous studies [31], which attributes more strength to our findings. Second, differently from previous studies [32, 33], we used a validated instrument for accessing the main exposure- maternal depressive symptomatology- and we identified each outcome (risk behavior) individually, not in clusters [33] providing more specificity to our results and justifying, in part, our negative findings. Finally, after attrition analysis, more privileged population was included in our study, and the magnitude of the association between the trajectories of maternal depression and offpring alcohol use and involvement in fights was more conservative.

Our study had some strengths: (1) a large populationbased sample with high response rate; (2) longitudinal assessments of maternal depression with a long follow-up time; (3) the use of validated instruments for assessing maternal depressive symptomatology (4) the adjustment for various maternal, familial, and child characteristics that potentially act as confounding variables for the associations being investigated; and (5) the study's contribution to the scarce literature in which the association between the trajectories of maternal depressive symptoms and engagement in health risk behaviors at age 11 are discussed.
The study also has some limitations. As nearly $20 \%$ of original cohort were not included in the analysis due to missing data, selection bias may have been introduced in our study. In the attrition analysis, we noticed that families with less purchasing power were excluded. We believe that as more privileged were included in our study, the impact of maternal depression trajectories in offspring behavior was probably underestimated and the magnitude of association found in our study is probably more conservative. Another limitation is the choice of a group-based model instead of a longitudinal growth model approach in the construction of the main exposure, which may have underestimated the importance of the predictive factors of the trajectories of maternal depression. Finally, there exist additional unmeasured risk factors that can act as potential confounders of the examined association and were not considered because data on these factors was not collected (ie. familial history of psychopathology and other diseases). This fact contributes to 'residual confounding' - an inherent issue of observational studies, but also a limitation of our study.

\section{Conclusion}

Differently for the scarce existing literature regarding trajectories of maternal depressive symptomatology and risky behavior in adolescents, we found no significant association between any trajectory of maternal depressive symptomatology and 'involvement in fights' and 'alcohol use' at age 11. Further associated factors should be investigated with the aim of preventing alcohol use and/or involvement in fights in early adolescence.

\section{Supplementary Information}

The online version contains supplementary material available at https://doi. org/10.1186/s12888-020-03026-9.

Additional file 1: Table 5. Comparison of maternal and child characteristics between those interviewed in both fifth and sixth followup waves (at 6 and 11 years old) and those interviewed in the fifth follow-up wave (at 6 years old) but absent in the sixth follow-up wave (at 11 years old) in the present study, 2004 Pelotas Birth Cohort.

\section{Acknowledgements}

The authors would like to thank the participating families and staff who collaborated in the various stages of the 2004 Pelotas Birth Cohort study.

\section{Authors' contributions}

$A B B$ undertook the analysis, interpreted the results and drafted the first version of the article. AM and JMM participated in the design and analysis of the study and collaborated with the interpretation of the findings and writing of the article. ISS, TNM, AJDB, FCB, collaborated with the interpretation of the findings and writing of the article. All authors approved the final version of the manuscript submitted.

\section{Funding}

This article is based on data from the 2004 Pelotas Birth Cohort study, conducted by the Postgraduate Program in Epidemiology of the Federal University of Pelotas, Brazil, with the support of the Brazilian Public Health Association (ABRASCO). From 2009 to 2013, the 2004 Pelotas Birth Cohort 
was supported by the Wellcome Trust (Grant no. 086974/Z/08/Z). Previous phases of the study were supported by the World Health Organization (Grant no. 03014HNI), National Support. Program for Centres of Excellence (PRONEX) (Grant no. 04/0882.7), Brazilian National Research Council (CNPq) (Grant no. 481012-2009-5; 484077-2010-4; 470965-2010-0; 481141-2007-3, 426024/2016-8), Brazilian Ministry of Health (Grant no. 25000.105293/200483) and Children's Pastorate. The 11-year follow-up was also funded by the São Paulo Research Foundation (FAPESP; grant no. 2014/13864-6). AJDB., I.S.S., F.C.B and A. M are supported by the CNPq. All the funding above contributed to the collection of data.

JMM is supported by a grant from Sao Paulo Research Foundation (FAPESP; Research Grant no. 2017/22723-5). ABB is supported by a scholarship from the Brazilian Federal Agency for Support and Evaluation of Graduate Education (CAPES). Both FAPESP and CAPES contributed for the analysis and interpretation of data, and writing of the manuscript.

\section{Availability of data and materials}

This article is based on data from the 2004 Pelotas Birth Cohort study, conducted by the Postgraduate Program in Epidemiology of the Federal University of Pelotas, Brazil, but restrictions apply to the availability of these data, which were used under license for the current study, and so are not publicly available.

\section{Ethics approval and consent to participate}

The study was approved by the Research Committee of the University of São Paulo School of Medicine, and by the Research Ethics Committee of the Federal University of Pelotas. At the 11-year follow-up, written informed consent was obtained from the mothers or legal guardians of the adolescents and adolescents also signed an informed consent form.

\section{Consent for publication}

Not applicable.

\section{Competing interests}

The authors have no conflicts of interest to declare.

\section{Author details}

'Departamento de Medicina Preventiva, Faculdade de Medicina FMUSP, Universidade de São Paulo, São Paulo, Brazil. ${ }^{2}$ Postgraduate Program in Epidemiology, Federal University of Pelotas, Pelotas, Brazil. ${ }^{3}$ Faculty of Psychology, Federal University of Pelotas, Pelotas, Brazil. ${ }^{4}$ Post-graduate Program in Health and Behavior, Catholic University of Pelotas, Pelotas, Brazil. ${ }^{5}$ Postgraduate Program in Pediatrics and Child Health, School of Medicine, Pontifical Catholic University of Rio Grande do Sul, Porto Alegre, Brazil.

Received: 22 July 2020 Accepted: 22 December 2020

Published online: 07 January 2021

\section{References}

1. Kipping RR, Campbell M, MacArthur GJ, et al. Multiple risk behaviour in adolescence. J Public Health. 2012;34(Issue suppl):1 i1-2. https://doi.org/10. 1093/pubmed/fdr122.

2. Eaton DK, et al. Youth risk behavior surveillance -United States, 2007. MMWR Surveill Summ. 2008;1:131.

3. Bird Y, Moraros J, Olsen LK, Coronado GD, Thompson B. Adolescents' smoking behaviors, beliefs on the risks of smoking, and exposure to ETS in Juarez, Mexico. Am J Health Behav. 2006;435:446.

4. Hockenberry JM, Edward JT, Vander WM. Smoking, parent smoking, depressed mood, and suicidal ideation in teens. Nicotine Tob Res. 2010;235:242.

5. Shonkoff JP, Garner AS, Siegel BS, et al. The lifelong effects of early childhood adversity and toxic stress. Pediatrics. 2012;129(1):e232-46.

6. Griesler PC, Kandel DB. The impact of maternal drinking during and after pregnancy on the drinking of adolescent offspring. J Stud Alcohol. 1998; 292:304.

7. Hutchinson DM, Alati R, Najman JM, et al. Maternal attitudes in pregnancy predict drinking initiation in adolescence. Aust N Zealand J Psychiatry. 2008; 324:334.

8. Baer JS, Barr HM, Bookstein FL, et al. Prenatal alcohol exposure and family history of alcoholism in the etiology of adolescent alcohol problems. J Stud Alcohol. 1998;533:543.
9. Dube SR, Miller JW, Brown DW, et al. Adverse childhood experiences and the association with ever using alcohol and initiating alcohol use during adolescence. J Adolesc Health. 2006;444:e1.

10. Slomian J, Honvo G, Emonts $\mathrm{P}$, et al. Consequences of maternal postpartum depression: a systematic review of maternal and infant outcomes. Women Health. 2019:15:1745506519844044.

11. Maruyama JM, Pastor-Valero M, Santos IS, et al. Impact of maternal depression trajectories on offspring socioemotional competences at age 11: 2004 Pelotas birth cohort. J Affect Disord. 2019;253:8-17.

12. Norhayati MN, Nik Hazlina NH, Asrenee AR, et al. Magnitude and risk factors for postpartum symptoms: a literature review. J Affect Disord. 2014;175:34-52.

13. Ashman SB, Dawson G, Panagiotides H. Trajectories of maternal depression over 7 years: relations with child psychophysiology and behavior and role of contextual risks. Dev Psychopathol. 2008;20:55-77.

14. Misri S, Reebye P, Kendrick K, et al. Internalizing behaviors in 4-year-old children exposed in utero to psychotropic medications. Am J Psychiatry. 2006;163(6):1026-32.

15. Matijasevich A, Murray J, Cooper PJ, et al. Trajectories of maternal depression and offspring psychopathology at 6 years: 2004 Pelotas cohort study. J Affect Disord. 2015;174:424-31.

16. Park M, Brain U, Grunau RE, et al. Maternal depression trajectories from pregnancy to 3 years postpartum are associated with children's behavior and executive functions at 3 and 6 years. Arch Womens Ment Health. 2018; 21:353-63.

17. Kingston $\mathrm{D}$, Kehler $\mathrm{H}$, Austin $\mathrm{M}$, et al. Trajectories of maternal depressive symptoms during pregnancy and the first 12 months postpartum and child externalizing and internalizing behavior at three years. PLoS One. 2018;13(4): e0195365. https://doi.org/10.1371/journal.pone.0195365.

18. Van Voorhees BW, Paunesku D, Kuwabara SA, et al. Protective and vulnerability factors predicting new-onset depressive episode in a representative of US adolescents. J Adolesc Health. 2008;605:616.

19. Fisher LB, Miles IW, Austin SB, et al. Predictors of initiation of alcohol use among US adolescents: findings from a prospective cohort study. Arch Pediatr Adolesc Med. 2007;959:966

20. Santos IS, Barros AJ, Matijasevich A, et al. Cohort profile: the 2004 Pelotas (Brazil) birth cohort study. Int J Epidemiol. 2011;40:1461-8.

21. Santos SI, Barros AJD, Matijasevich A, et al. Cohort profile update: 2004 Pelotas (Brazil) birth cohort study. Body composition, mental health and genetic assessment at the 6 years follow-up. Int J Epidemiol. 2014;43:1437.

22. Cox JL, Holden JM, Sagovsky R. Detection of postnatal depression. Development of the 10-item Edinburgh postnatal depression scale. $\mathrm{Br} J$ Psychiatry. 1987;150:782-6.

23. Santos IS, Matijasevich A, Tavares BF, et al. Validation of the Edinburgh postnatal depression scale (EPDS) in a sample of mothers from the 2004 Pelotas birth cohort study. Cad Saude Publica. 2007;23:2577-88.

24. Nagin DS. Group-based modeling of development. Cambridge: Harvard University Press; 2005

25. Azeredo CM, Santos IS, Barros AJD, et al. Maternal depression and bullying victimization among adolescents: results from the 2004 Pelotas cohort study. Depress Anxiety. 2017:34:897-907.

26. Wechsler D. Wechsler intelligence scale for children (WISC-III): manual. San Antonio: The Psychological Corporation; 1991.

27. Victora CG, Huttly SR, Fuchs SC, Olinto MTA. The role of conceptual frameworks in epidemiological analysis: a hierarchical approach. Int J Epidemiol. 1997;26:224-7.

28. Murray L, Arteche A, Fearon P, et al. Maternal postnatal depression and the development of depression in offspring up to 16 years of age. J Am Acad Child Adolesc Psychiatry. 2011;50(5):460-70.

29. Goodman SH, et al. Maternal depression and child psychopathology: a meta-analytic review. Clin Child Fam Psychol Rev. 2011;14:1-27.

30. Brennan PA, Hammen C, Andersen MJ, et al. Chronicity, severity, and timing of maternal depressive symptoms: relationships with child outcomes at age 5. Dev Psychol. 2000;36(6):759.

31. Wickham ME, Senthilselvan A, Wild TC, et al. Maternal depressive symptoms during childhood and risky adolescent health behaviors. Pediatrics. 2015; 135(1):59-67.

32. Flouri $\mathrm{E}$, loakeimidi S. Maternal depressive symptoms in childhood and risky behaviours in early adolescence. Eur Child Adolesc Psychiatry. 2018;27(3):301-8

33. Campbell SB, Morgan-Lopez AA, Cox MJ, McLoyd VC. A latent class analysis of maternal depressive symptoms over 12 years and offspring adjustment in adolescence. J Abnorm Psychol. 2009;118(3):479. 
34. Lawlor DA, Batty GD, Morton SM, Deary IJ, Macintyre S, Ronalds G, Leon DA. Early life predictors of childhood intelligence: evidence from the Aberdeen children of the 1950s study. J Epidemiol Community Health. 2005;59(8):656-63.

35. Murray J, Maughan B, Menezes AM, Hickman M, MacLeod J, Matijasevich A,

Barros FC. Perinatal and sociodemographic factors at birth predicting conduct problems and violence to age 18 years: comparison of Brazilian and British birth cohorts. J Child Psychol Psychiatry. 2015;914:922.

\section{Publisher's Note}

Springer Nature remains neutral with regard to jurisdictional claims in published maps and institutional affiliations.

Ready to submit your research? Choose BMC and benefit from:

- fast, convenient online submission

- thorough peer review by experienced researchers in your field

- rapid publication on acceptance

- support for research data, including large and complex data types

- gold Open Access which fosters wider collaboration and increased citations

- maximum visibility for your research: over $100 \mathrm{M}$ website views per year

At $B M C$, research is always in progress.

Learn more biomedcentral.com/submissions 